\title{
Comment
}

DO WE KNOW THE VALUE OF WHAT WE ARE DOING?

\section{Assessing scientific citizenship through science centre visitor studies}

\section{Andrea Bandelli}

\begin{abstract}
As science museums and centres (SMC) broaden their practices to include the development of scientific citizenship, evaluation needs also to take account of this dimension of their practices. It requires complex methods to understand better the impacts of public participation in activities mediated by $S M C$, including their impacts on the governance of the SMC themselves.
\end{abstract}

Science museums and centres (SMC) are traditionally recognised as institutions of informal science learning. Their exhibitions and programmes help visitors to explore and investigate science and technology, to raise questions about our world, and to stimulate curiosity and inquiry. Much effort has been put into evaluating the impact of science centres on the learning that occurs during and after a visit to a science centre.

In recent years, however, science centres and museums are expanding their mission beyond informal science learning, and they are becoming places that support the scientific citizenship of their visitors [1].

Some exhibitions and programmes present the controversial aspects of contemporary research, rather than (or together with) the more established knowledge of academic science. Some institutions even have real laboratories built in the museum where scientists pursue their research activity in full view and contact with the public.

In this way visitors can interact with the researchers and question the very act of what it means to "do science". At the same time, the scientists working in these labs are exposed to the questions, hopes, and curiosity of lay citizens, and the daily interactions with the public become a normal feature of their professional work. This kind of public engagement with science works in both directions - it engages the public with science, and science, or better, scientists, with the public [2].

These informal engagement activities are being recognised as having impacts on scientific culture, politics and society [3]. But the impacts of science centres on policy are not confined to the informal domain any more. Projects like Meeting of Minds or Polka $[4,5]$ involved several SMC where formal policy statements in the field of neurological and genetic research were formulated and subsequently brought to the European institutions. In 
2013 the European Commission organised the largest formal public consultation to inform the development of the new framework programme for scientific research in collaboration with 33 SMC in Europe [6]. In the PLACES project (see also Gema Revuelta's contribution to this Commentary) science centres, festivals and museums in more than 60 cities collaborate with local governments and universities to develop science culture policies.

Science centres and museums are thus effectively enabling two components of scientific citizenship, the scientific competence dimension and the participation dimension. How science centres strengthen scientific competence has been studied in various domains - from the perspective of learning, engagement, literacy, etc. There is still much to understand instead about how they support the participation dimension of scientific citizenship. Basic questions, such as the extent to which the public is aware of science centres as platforms for scientific citizenship, have yet to be tackled. The strategies and modalities to enable participation in SMC also require a much deeper understanding.

Qualitative research has been widely used to assess dialogue and participation activities, and it is so far the preferred choice to evaluate how science centres enable scientific citizenship. But there are a number of limitations in this approach that call for a broader discussion. First is the need for a more systematic definition of scientific citizenship, so that science centres can use it to consistently evaluate their own activities. Second, qualitative research is not always well suited to support comparative and cross-cultural studies, and there are both methodological and practical limitations for science centres to benefit from qualitative research. In this perspective, a more widespread use of quantitative methods will help to overcome the structural limitations of qualitative research for the assessment of scientific citizenship.

We need to understand better the impact of the participation activities that take place in science centres on policy, governance and other decision-making processes, both inside and outside the institution. The science centre field has collectively developed the competences to promote and develop a broad spectrum of participation programmes, from small-scale informal dialogue events to international structured consultation exercises. Yet, it is still difficult to assess fully the impact of such activities, which often have "ripple effects" that go well beyond the stated intentions of each project.

Even more important is to study the scope of these participation activities. Museum visitors can express their scientific citizenship in various contexts: in the museum itself and outside the museum, through their social network of organisations and individuals they are connected to. At the institutional level, public participation can be argued on the basis that science centres produce and mediate scientific culture with the public. How this translates into effective methods for public participation in the governance of the science centre is subject to a number of factors which we are recently starting to study and understand [7].

In several cases, however, science centres are also fulfilling the role of "brokers", connecting the public with stakeholders in the governance of science. These include the European Commission, local municipalities, universities, research centres, industries, civil society organisations and many others. Enabling scientific citizenship means that science 
centres are constantly re-defining the nature of their public (as spectators, as engaged citizens, and maybe even as activists) but also how the public enacts itself in the interactions with the other stakeholders. Understanding the role played by the science centre in this process becomes therefore crucial. It means studying the complex relationships and relative influence of science centres with other stakeholders and with their public.

This is an exciting field of research, where we need broader discussions going beyond the traditional science centre field in order to understand and set priorities, methods, and eventually develop much-needed evaluation tools.

\section{References}

[1] P. Greco (2007), "Science museums in a knowledge-based society", JCOM 6(2): C02.

[2] M. Meyer (2011), "Researchers on display: moving the laboratory into the museum", Museum Management and Curatorship 26(3): 261-272.

[3] L. Stilgoe, S.J. Lock and J. Wilsdon (2014), "Why should we promote public engagement with science?", Pub. Underst. Sci. 23(1): 4-15.

[4] I. Anderson, S. Joss, K. Ng, G. Rauws, S. Steyaert, R. van Est, and T. Vandensande (2007), "European Citizens Deliberation. Method Description", S. Steyert and T. Vandensande eds., King Baudouin Foundation, Brussels, Belgium.

[5] J. Parisse-Brassen (2009), POLKA: Patients' Consensus on Preferred Policy Scenarii for Rare Disease, online at: http://www.eurordis.org/content/polka-patients-consensus-preferred-policyscenarii-rare-disease, accessed 3 January, 2012.

[6] See http://voicesforinnovation.eu/.

[7] A. Bandelli and E.A. Konijn (2012), "Science Centres and Public Participation: Methods, Strategies, and Barriers", Sci. Commun. 35(4): 419-448.

\section{Author}

Andrea Bandelli is currently conducting Ph.D. research at the VU University Amsterdam, The Netherlands, on the role of the public in the governance of science centers. E-mail: andrea@bandelli.com.

How TO CITE: A. Bandelli, Assessing scientific citizenship through science centre visitor studies, JCOM 13(01)(2014)C05. 